\title{
Institucionalização da Ciência da Informação no Brasil: estudo da convergência entre a produção científica e os marcos regulatórios da área
}

\author{
Institutionalization of Information Science in Brazil: study of \\ the convergence between the scientific production and \\ regulatory landmarks of the area
}

Regiane Alcântara ELIEL'

\begin{abstract}
RESUMO
O presente trabalho tem como objetivo estudar o desenvolvimento e a institucionalização da Ciência da Informação no Brasil, analisando o grau de convergência entre a produção científica - materializada em teses e dissertações - e os marcos regulatórios da área (Documento de Área da CAPES e Grupos Temáticos da ANCIB). O objeto empírico da pesquisa é constituído de dados referenciais de teses e dissertações da Ciência da Informação, analisados por meio de métodos cientométricos. Conclui-se que as teses e dissertações apresentam convergência parcial com os marcos regulatórios da área e que a Ciência da Informação precisa superar alguns desafios, tais como: o de diminuir o elevado número de estudos direcionados para a prática; o de garantir a produção de pesquisas teóricas e conceituais, em detrimento das pesquisas que visam à resolução de problemas concretos e localizados; o de definir o objeto de estudo da área, evitando-se a dispersão temática existente e, além disso, o de garantir maior índice de crescimento dos programas de Pós-graduação, principalmente em relação aos cursos de doutorado para, então, garantir sua institucionalização social e cognitiva efetiva.
\end{abstract}

Palavras-chave: institucionalização da Ciência da Informação; aspectos teóricos da Ciência da Informação; métodos cientométricos; teses e dissertações.

\section{ABSTRACT}

The objective of the present study is to show the development and the institutionalization of Information Science in Brazil, analyzing the degree of convergence between the scientific production - materialized in thesis and dissertations - and landmarks (Documento de Área da CAPES e Grupos Temáticos da ANCIB). Its empirical object is constituted of references data of thesis and dissertations of information science, analyzed using of scientometrics methodology. Finally, the thesis and dissertations present partial convergence with landmarks, and the information science necessities to surpass some challenges such as to diminish the high number of studies concerning the practice; to guarantee the production of theoretical and conceptual research, in detriment of the research that aims to solve concrete and focused problems, and to define the object of study of the area,

\footnotetext{
1 Mestre em Ciência da Informação pela PUC-Campinas. Bibliotecária, Instituto de Filosofia e Ciências Humanas, Universidade Estadual de Campinas. Rua Cora Coralina, Cidade Universitária, 13081-970, Campinas, SP, Brasil. E-mail: <regiane@unicamp.br>. Recebido em 3/7/2007 e aceito para publicação em 1/11/2007.
} 
avoiding its thematic dispersion and, moreover, promote greater index of growth of the Post-Graduation programs, mainly in relation to the courses of doctorate to guarantee its effective social and cognition institutionalization.

Keywords: Information Science institutionalization; Information Science theoretical aspects; scientometrics methodology; thesis and dissertations

\section{INTRODUÇÃO}

A institucionalização de uma disciplina, conforme aponta Parlemiti e Polity (2002), está relacionada a duas dimensões: institucionalização cognitiva e institucionalização social.

A institucionalização cognitiva está relacionada aos conhecimentos que são próprios da área, ou seja, aos conceitos consensuais, aos problemas abordados, à aceitabilidade das soluções, aos métodos, aos instrumentos, às técnicas etc. Já a institucionalização social está ligada à criação de estruturas formais que dão visibilidade e que estabelecem as bases sociais para os membros da comunidade científica, ou seja, está relacionada com a criação e formalização de cursos e universidades, com o desenvolvimento de sociedades de classe, com os conhecimentos produzidos e publicados, com a promoção de eventos etc.

A institucionalização social de uma disciplina, sua implementação e formalização dependem da criação de estruturas acadêmicas de ensino e de pesquisa e tal fator, depende, em grande medida, dos esforços do Estado, por meio de seus órgãos representativos como o MEC e a CAPES, que estabelecem parâmetros para criação e manutenção de estruturas formais que demarcam dada disciplina.

A institucionalização social da Ciência da Informação parece ter sua origem na Biblioteconomia, já que a Ciência da Informação beneficiou-se das estruturas formais da Biblioteconomia para tecer seu desenvolvimento e institucionalização social. Isso fica evidente quando Robredo (2003, p. 88) indica que:

\footnotetext{
A partir de meados da década de 80 os cursos de Biblioteconomia do país, acompanhando o que vinha acontecendo em países de economia avançada, começam a mudar os nomes dos cursos de graduação em Biblioteconomia, e os cursos de pós-graduação que vão sendo criados já nascem com nomes que incluem a expressão Ciência da Informação.
}

A literatura evidencia que o desenvolvimento da Ciência da Informação no Brasil mantém estreita relação com o estabelecimento dos cursos de pós-graduação e dos grandes sistemas de informação que pretendiam potencializar o fluxo de informações científicas no país.

De acordo com Miranda e Barreto (2000, p. 3),

\begin{abstract}
A criação do IBBD, da Bireme, das tentativas pela implantação de um sistema de informação agrícola e outro para as engenharias, a organização do Comut etc, foi decisivo para o processo de criação dos cursos de pós-graduação em Ciência da Informação na medida em que criou um ambiente adequado para a problematização das questões que motivaram as pesquisas e criaram a demanda para a formação de massa crítica.
\end{abstract}

Assim, o estabelecimento da pós-graduação e da pesquisa em Ciência da Informação no Brasil se dá em função desse novo cenário, no qual há uma crescente demanda por pesquisas capazes de respaldar o desenvolvimento dos sistemas de informação que se estavam estabelecendo no país.

No entanto, conforme relatam Miranda e Barreto (2000), o estabelecimento da pós-graduação e da pesquisa da Ciência da Informação (institucionalização social) no Brasil foi criticado por não ter sido feita uma definição prévia do conceito de Ciência da Informação (institucionalização cognitiva).

Esse cenário parece ainda não ter sofrido alterações significativas. Tal afirmativa se respalda no posicionamento de Gomes (2006, p. 2):

Há um reconhecimento entre os pesquisadores
de que a Biblioteconomia e a Ciência da Infor-
mação não contam com teorias capazes de
abarcar todo o universo de problemas dessas
áreas e propor hipóteses para pesquisas e, as-
sim, chegar a descobertas que levem a novos 
conhecimentos teóricos. Apontam, assim, fragilidades teóricas e metodológicas como obstáculos à condução de pesquisas.

A fragilidade teórica e conceitual da Ciência da Informação também foi apontada por Pinheiro e Loureiro (1995, p. 3):

\begin{abstract}
Tem sido assinalada a ausência, na área, de um corpo de fundamentos teóricos que possam delinear o seu horizonte científico, e ainda se encontra em construção a epistemologia da Ciência da Informação ou a investigação dos conhecimentos que a permeiam. A falta de estudos nessa linha e, mesmo, a presença incipiente de teóricos, mantém a Ciência da Informação em um estado de fragilidade teórico-conceitual.
\end{abstract}

Ao que tudo indica, no campo da Ciência da Informação, as questões práticas têm sido tratadas em detrimento das questões teóricas e epistemológicas.

Wersig (1993, p. 230) corrobora essa idéia ao afirmar que "as soluções oferecidas, até o momento, caracterizam-se como campos de reflexão ou experiências práticas, não em ciência em seu sentido clássico". É importante ressaltar que o autor não considera a Ciência da Informação como uma ciência clássica, elevando-a ao nível das ciências pós-modernas (voltadas para o trato de novos problemas), no entanto, enquanto ciência, a Ciência da Informação carece de uma teoria, de um corpo conceitual que fundamente seu desenvolvimento científico.

Embora a avaliação trienal da CAPES (2001 2003) demonstre um pequeno avanço da área, apontando que a inserção das pesquisas no campo teórico da Ciência da Informação e que o aumento da produção bibliográfica têm sido essenciais para esse novo cenário, é necessário considerar que a própria CAPES tem apontado que a produção científica do campo é ainda bastante tímida e raramente visa à generalização ou à teorização, havendo um baixo índice de estudos teóricos e uma tendência à abordagem de questões de ordem empírica.

Portanto, para que a Ciência da Informação tenha suas estruturas científicas estabelecidas e fundamentadas, é necessário solidificar as bases da sua institucionalização cognitiva e social, ou seja, é necessário estabelecer de forma consensual as questões teóricas e epistemológicas da área, seus conceitos, seu objeto de estudo, suas conexões interdisciplinares, suas linhas de pesquisas.

Com base no exposto, assumindo como hipótese que a Ciência da Informação é uma disciplina cuja institucionalização ainda não está totalmente estabelecida, a pesquisa desenvolvida pretendeu analisar o desenvolvimento e a institucionalização da Ciência da Informação no Brasil, com a finalidade de identificar os elementos significativos para a apreensão do grau de institucionalização social e cognitivo da Ciência da Informação e analisar a configuração da área no país, a partir da análise da convergência entre a produção científica e os marcos regulatórios da área - o conceito de marco regulatório representa as regras, normas e formalidades que regem o campo da Ciência da Informação no contexto brasileiro. Assim, são considerados como marcos regulatórios o Documento de Área da CAPES (Coordenação de Aperfeiçoamento de Pessoal de Nível Superior) e os grupos de temáticos da ANCIB (Associação Nacional de Pesquisa e PósGraduação em Ciência da Informação). Tais elementos são considerados como marcos regulatórios por apresentarem diretrizes, instruções e normas de desenvolvimento e aperfeiçoamento da Ciência da Informação.

Parlemiti e Polity (2002) afirmam que a institucionalização de uma disciplina pode ser estudada a partir de uma análise histórica dos processos que caracterizam essa institucionalização. Dentre os critérios que permitem mensurar a evolução de uma disciplina, os autores mencionam "as formações universitárias, as equipes de pesquisas, as publicações, as revistas, as teses, os lugares de encontro, tais como: os colóquios, seminários, congressos, os manuais que contribuem com a transmissão de conceito e terminologia de base e as aquisições fundamentais".

No contexto da pesquisa desenvolvida, a institucionalização da Ciência da Informação foi estudada a partir do objeto empírico da pesquisa, cujo corpus constitui-se a partir de dados referenciais de teses e dissertações defendidas nos Programas de PósGraduação em Ciência da Informação do país, no período de 1978 a 2001, que foram explorados por meio de análises cientométricas. 


\section{PROCEDIMENTOS METODOLÓGICOS}

Objeto empírico da pesquisa constituiu-se a partir dos dados referenciais de teses e dissertações da Ciência da Informação, que foram analisados por meio de métodos cientométricos.

A cientometria é um método quantitativo utilizado para analisar o comportamento e as atividades da ciência, partindo-se da sua produção e comunicação.

De acordo com Spinak (1998, p. 142), como instrumento indispensável para a tomada de decisão na esfera das políticas públicas, particularmente em relação às prioridades a serem estabelecidas.

Spinak (1998, p. 142) aponta que:
A cientometria aplica técnicas da bibliometria à ciência. $\bigcirc$ termo ciência se refere às ciências físicas, naturais, assim como às ciências sociais. Portanto, a cientometria vai além das técnicas bibliométricas, pois examina o desenvolvimento e as políticas científicas. As análises quantitativas da cientometria consideram a ciência como uma disciplina ou atividade econômica. Por essa razão, a cientometria pode estabelecer comparações entre as políticas de investigação entre países, analisando seus aspectos econômicos e sociais².

Parafraseando Kobashi e Santos (2006), verificase que a cientometria e a bibliometria apresentam semelhanças quanto a alguns aspectos operacionais e campo de aplicação: ambas ocupam-se do desenvolvimento de metodologias para análise e construção de indicadores e baseiam-se na construção de indicadores, tendo como ponto de partida os documentos publicados, que são analisados quanto à quantidade, autoria, citações, temas abordados e outros aspectos.

Macias-Chapula (1998, p. 134) considera que a cientometria "é o estudo dos aspectos quantitativos da ciência enquanto uma disciplina ou atividade econômica. A cientometria é um segmento da sociologia da ciência, sendo aplicada no desenvolvimento de políticas científicas [...]".

Van Raan (2003) indica que o método bibliométrico (incluindo a cientometria) configura-se
Os temas que interessam à cientometria ${ }^{3}$ incluem o crescimento quantitativo da ciência, o desenvolvimento de disciplinas e subdisciplinas, a relação entre ciência e tecnologia, a obsolescência dos paradigmas científicos, a estrutura da comunicação entre os cientistas, a produtividade e criatividade dos investigadores, a relação entre desenvolvimento científico e crescimento econômico etc ${ }^{4}$.

Assim, verifica-se que as técnicas avançadas da cientometria são instrumentos que permitem a análise dos dados bibliográficos das teses e dissertações produzidas no âmbito da Ciência da Informação brasileira, permitindo o mapeamento dos temas de pesquisa, orientadores, linhas de pesquisa e o estudo do desenvolvimento e institucionalização dessa Ciência no Brasil.

\section{Corpus - Objeto Empírico}

A pesquisa teve como objeto empírico os dados referenciais das teses e dissertações defendidas em sete programas de pós-graduação em Ciência da Informação, no período de 1978-2001, totalizando 833 registros, sendo 749 dissertações de mestrado e 84 teses de doutorado.

Os programas que tiveram suas teses e dissertações analisadas foram os seguintes:

- Programas com cursos de mestrado e doutorado:

1 - UFF/IBICT: as atividades do Programa de Pós-Graduação em Ciência da Informação da UFF/ IBICT foram iniciadas em 1970, com a criação do curso de mestrado pelo então Instituto Brasileiro de Bibliografia

\footnotetext{
2 Original em espanhol.

3 Bufrem e Prates (2005) traduziram o termo scientometrics como cientometria. Os autores apontam que, na literatura especializada em português e espanhol, o termo cienciometria é comumente utilizado. No entanto considera-se que o termo cientometria é a tradução adequada do neologismo inglês. No contexto da presente pesquisa também é adotado o termo cientometria.

4 Original em espanhol.
} 
e Documentação (IBBD) - hoje IBICT - em convênio com a Universidade Federal do Rio de Janeiro (UFRJ). O programa criou seu curso de doutorado em 1992 e a partir de 2003 passou a ser administrado pela UFF e pelo IBICT;

2- UFMG: o Programa de Pós-Graduação em Ciência da Informação da UFMG iniciou suas atividades em 1976, com a criação do curso de mestrado, e em 1997 foi criado o curso de doutorado;

3- UNB: o Programa de Pós-Graduação em Ciência da Informação e Documentação da UNB possui curso de mestrado e de doutorado, criados, respectivamente, em 1978 e 1992;

4- UNESP: o Programa de Pós-Graduação em Ciência da Informação da UNESP também conta com curso de mestrado e de doutorado, tendo sido o primeiro foi criado em 1998 e o último em 2004.

5- USP: além dos programas mencionados acima, também foram analisadas as teses e dissertações dos cursos de mestrado e doutorado do Programa de Pós-Graduação em Ciências da Comunicação da USP (criados, respectivamente, em 1972 e 1980), que tinham a Ciência da Informação como área de concentração. Esses cursos só passaram a ser autônomos com a criação do Programa de Pós-Graduação em Ciência da Informação, em 2006.

- Programas com cursos de mestrado:

1 - PUC-Campinas: O Programa de PósGraduação em Ciência da Informação da PUCCampinas iniciou suas atividades em 1977, com a criação do curso de mestrado.

2- UFPB: o curso de mestrado da UFPB foi criado em 1978. Interrompeu suas atividades em 2001, retomando-as no ano de 2006.

Neste momento, é relevante destacar que as teses e dissertações foram definidas como alvo do objeto empírico desta pesquisa, em função do compartilhamento da idéia defendida por Parlemiti e Polity (2002), que indicam que as teses e dissertações, dentre todas as demais atividades científicas - artigos de revistas ou trabalhos de eventos -, seguem padrões científicos mais rigorosos, sendo elaboradas sob supervisão de um orientador reconhecido pelas autoridades disciplinares legítimas. Além disso, as teses e dissertações refletem as atividades de pesquisa institucional e, teoricamente, devem estar em consonância com marcos que regulam a área e estabelecem as diretrizes para o desenvolvimento do campo.

Kobashi, Santos e Carvalho (2006, p. 2) corroboram essa idéia ao afirmarem que "a produção de dissertações e teses se dá em contextos altamente institucionalizados e controlados, contando atualmente com massa significativa de dados que não foram, ainda, analisados sistematicamente".

\section{Procedimentos de Coleta de Dados}

Os dados bibliográficos do período de 1978 2001 foram obtidos a partir da base referencial de teses e dissertações mantida pela CAPES. Tal recorte justificase em função da defasagem de atualização da referida base de dados. A intenção inicial era analisar os dados das teses e dissertações, do período de 1978-2005. No entanto, como os dados da CAPES abrangem até 2001, percebeu-se que, em função da defasagem da base, seria necessário estabelecer outros meios de recuperação dos dados das teses e dissertações.

A primeira estratégia foi contatar as bibliotecas dos programas, visando à captação de tais dados. Infelizmente, essa etapa do trabalho não logrou sucesso, visto que as bibliotecas não responderam à solicitação, com exceção da Biblioteca da PUC-Campinas.

A estratégia seguinte foi estabelecer contato com os coordenadores e professores dos programas de pósgraduação. Com isso, a UNB e a USP encaminharam seus dados. Mas, ainda assim, alguns programas não atenderam à solicitação encaminhada.

Por questões de cronograma - expiração do prazo para conclusão da fase de coleta de dados - julgou-se necessário realizar um corte no período de análise, assumindo como objeto da pesquisa os dados das teses e dissertações produzidas entre 1978-2001 - ressaltase que nem todos os programas apresentavam os dados de 2001 atualizados na base da CAPES. Tal decisão foi tomada com base na idéia de que os dados deveriam ser comuns a todas as instituições consideradas. Com efeito, a análise parcial dos dados inviabilizaria sua comparação, haja vista que algumas universidades teriam seus dados integralmente analisados e outras não, o que geraria distorção nos resultados. 
Para garantir a geração de resultados consistentes, a coleta dos dados foi feita de maneira exaustiva e rigorosa, tanto que alguns resumos foram coletados in loco, nas bibliotecas da PUC-Campinas e da USP.

O período da coleta de dados foi uma etapa importante da pesquisa, ressaltando a necessidade de se terem os dados da produção científica brasileira organizados e sistematizados, pois a falta de organização impossibilitou o acesso aos dados e mudou o percurso inicialmente traçado para a pesquisa.

\section{Procedimentos de Formatação dos Dados}

Os registros bibliográficos coletados apresentavam, via de regra, a seguinte estrutura: autor, título, orientador, grau, localização, escola, ano de defesa, palavras-chave e resumo.

A partir da análise de tais elementos, identificouse que apresentavam inúmeros tipos de erros e inconsistências os quais, se não corrigidos, comprometeriam a confiabilidade das análises cientométricas.

Kobashi e Santos $(2006$, p. 6) identificaram a precariedade das bases de dados sobre a produção científica brasileira e apontam:

E alarmante o grau de desorganização, dispersão e falta de padronização dos repositórios de produção científica nacionais. Os autores consideram que "esses fatos indicam que a realização de análises rigorosas, qualquer que seja a área de conhecimento considerada, encontra barreiras muitas vezes intransponíveis."

As inconsistências consistiam na não padronização dos nomes de orientadores, das escolas e dos programas; na atribuição de descritores extremamente genéricos ov extremamente específicos; na utilização de diferentes formas de expressão para conceitos equivalentes e atribuição excessiva ou insuficiente de descritores.

A partir de tal constatação, julgou-se necessário realizar um exaustivo trabalho de reformatagem e padronização dos elementos bibliográficos, constituindo uma base ad hoc.

Com o objetivo de garantir maior rigor ao trabalho de reformatagem dos dados, foi desenvolvida uma metodologia de indexação e padronização dos elementos bibliográficos. Tal metodologia estabeleceu a criação de alguns campos considerados essenciais para o andamento da pesquisa:

- Descritores: campo onde os descritores foram registrados;

- Macro-descritores: foi criado para registrar os grupos temáticos da $\mathrm{ANCIB}$, definidos a partir do encaixe dos descritores nas ementas dos grupos.

- Método: criado para registro dos métodos e dos tipos de pesquisa informados nas teses e dissertações.

O trabalho de reformatação foi longo e exaustivo, pois a falta de padronização dos dados e dos resumos dificultou a compreensão e a extração das informações, além de, via de regra, os resumos se mostrarem vagos e pouco esclarecedores, não apresentando os objetivos das pesquisas, a metodologia utilizada e a conclusão dos trabalhos.

Além disso, a leitura técnica dos resumos demonstrou que parece haver uma falta de clareza do que seja tipologia de pesquisa cientifica, método e instrumentos metodológicos. Assim, para fins de adequação e entendimento das abordagens metodológicas, foi elaborada uma tabela (lista) de classificação dos métodos e tipos de pesquisas, tendo como base os estudos realizados por Oliveira (2005, p. 4-5) e Gomes (2005, p. 3).

O processo de coleta e padronização dos dados das teses e dissertações explicitou que a pesquisa enquanto atividade científica deve assegurar a preservação de padrões, ou seja, explicitou, por meio da prática, aquilo que já se sabe na teoria.

Nesse sentindo, é pertinente a colocação de Macias-Chapula (1998, p. 136) ao mencionar que

[...] na verdade, a ciência necessita ser considerada como um amplo sistema social, no qual uma de suas funções é disseminar conhecimentos. Sua segunda função é assegurar a pre- 
servação de padrões, e a terceira é atribuir créditos e reconhecimento para aqueles cujos trabalhos têm contribuído para o desenvolvimento das idéias em diferentes campos.

Diante disso, destaca-se que as teses e dissertações devem garantir a preservação de padrões tanto no desenvolvimento da pesquisa científica quanto em relação à qualidade e padronização dos seus elementos referenciais (dados bibliográficos e resumos).

\section{Procedimentos de Análise dos Dados}

Após sua padronização, iniciou-se o processo de análise dos dados, por meio da aplicação de métodos cientométricos, que forneceram as representações da pesquisa em Ciência da Informação no Brasil. Para tanto, foram utilizados os seguintes softwares:

1: Infotrans: programa da empresa alemã IUK, foi utilizado para transformar os registros bibliográficos em registros bibliométricos, no caso, em registros cientométricos, realizando processos de eliminação de registros duplicados e de identificação de inconsistências.
2: Dataview: programa elaborado pelo Centre de Recherche Rétrospective de Marseille (CRRM) da Universidade Aix-Marseille, Centre de St. Jérôme, Marselha, França, foi utilizado para análise de nível micro, como contagem de dados e registros.

3: Excel: programa da Microsoft que foi utilizado na geração de gráficos.

A partir das análises cientométricas, os resultados foram analisados com o objetivo de verificar a convergência entre a produção científica do campo e os marcos regulatórios da área.

É importante destacar que, no processo de análise dos temas presentes nas teses e dissertações, considerou-se apenas aqueles que apresentaram freqüência igual ou superior a 9. Também foi realizado um recorte na análise dos dados que representavam a relação entre orientadores versus o número de orientações realizadas. Nesse caso, consideraram-se apenas os orientadores que orientaram um número igual ou superior a 10 teses e/ou dissertações. Tais recortes foram realizados em função da grande dispersão existente a partir das freqüências aqui citadas.

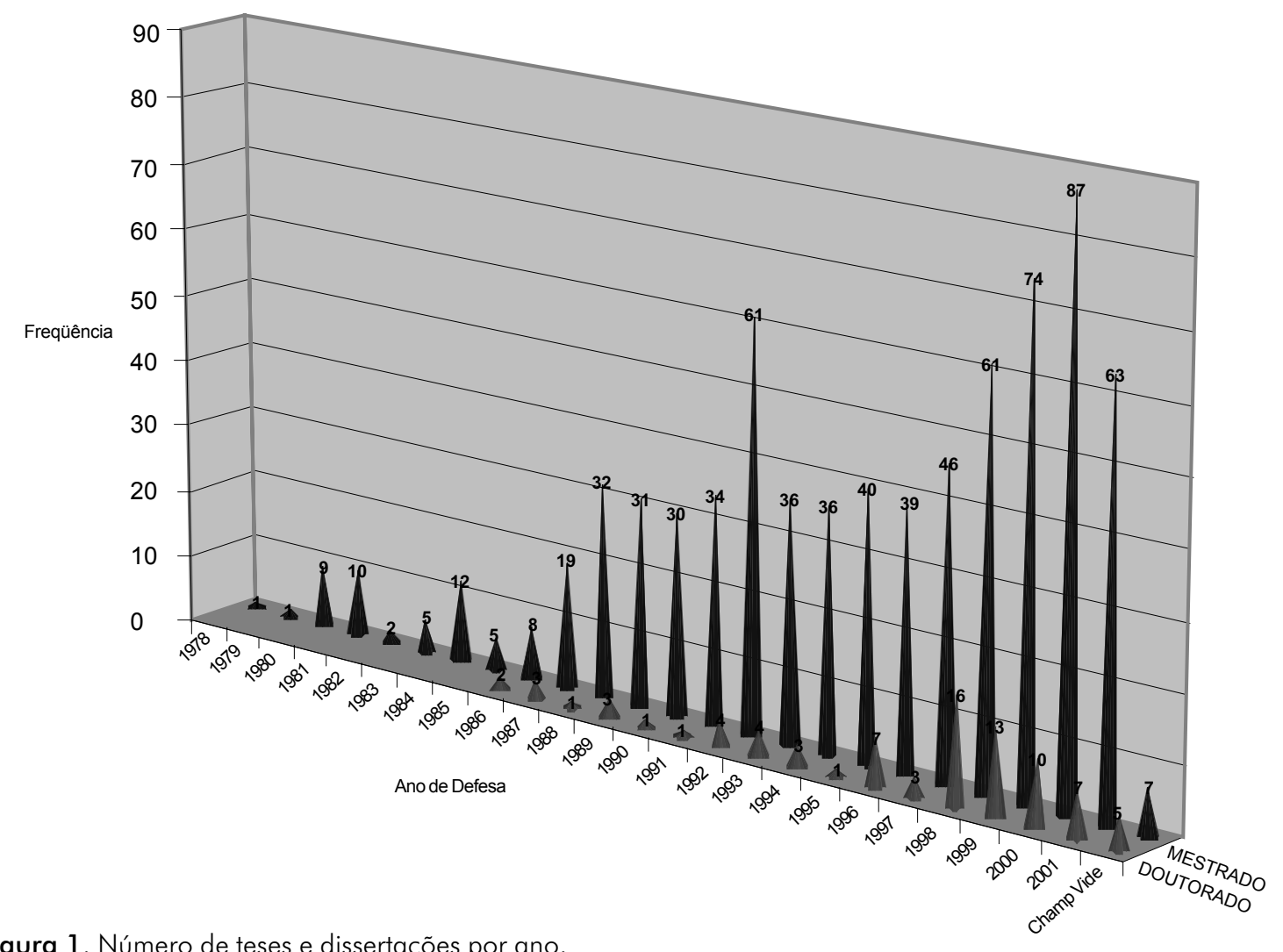

Figura 1. Número de teses e dissertações por ano. 


\section{ANÁLISE DOS DADOS}

A Figura 1 apresenta o número global de teses e dissertações produzidas pelos programas de pósgraduação em Ciência da Informação do país, no período de 1978-2001. A representação gráfica revela que, no ano de 1978, a produção foi de apenas uma dissertação e que os anos seguintes são marcados por uma linha ascendente de crescimento. O gráfico mostra, ainda, que o número de títulos de doutorado concedido no período pesquisado é bastante inferior ao número de títulos de mestrado. Essa constatação reforça as indicações da CAPES, em sua última avaliação, na qual apontou que, embora a concessão de títulos de doutorado seja crescente nos últimos anos, a área não tem acompanhado o grau de desenvolvimento de outras áreas das Ciências Sociais Aplicadas.

A CAPES considera que o desenvolvimento da Ciência da Informação tem sido lento e que a área carece de um crescimento mais intenso, tanto no sentido quantitativo quanto qualitativo. Para tanto, indica que os programas devem ser capazes de formar bons pesquisadores, integrar a(s) área(s) de concentração, as linhas de pesquisa, os projetos de pesquisa, a produção intelectual e estrutura curricular, desenvolver teses e dissertações com elevado grau de qualidade, com fundamentação teórica adequada ao objeto da área, com rigor metodológico e com pesquisas capazes de contribuir para o desenvolvimento da Ciência da Informação.

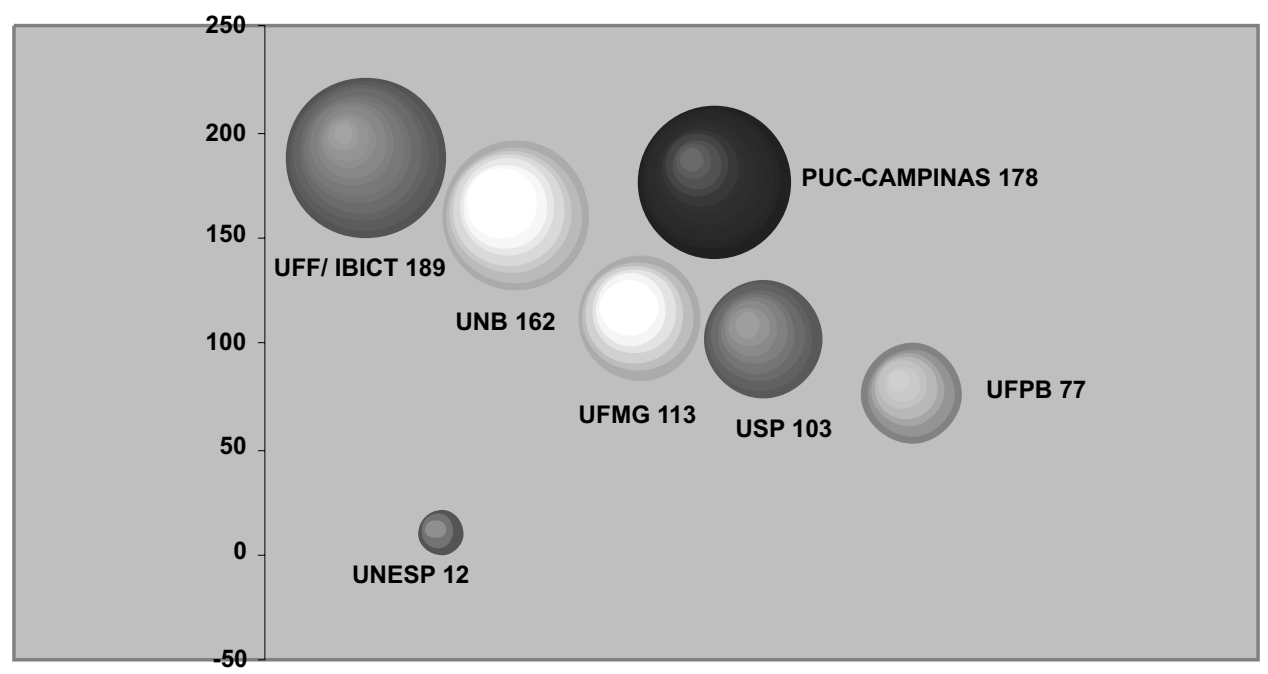

Figura 2. Número de títulos concedidos por instituição.

A Figura 2 apresenta a distribuição do número de teses e dissertações produzidas por cada um dos programas de Pós-graduação em Ciência da Informação, demonstrando que o programa da Universidade Federal Fluminense (UFF) e do Instituto Brasileiro de Informação em Ciência e Tecnologia (IBICT) apresenta a maior produção no período considerado. Esse fato justifica-se porque o programa da UFF/ IBICT possui o mais antigo curso de mestrado do país, tendo sido criado em 1970 pelo então Instituto Brasileiro de Bibliografia e Documentação (IBBD) - hoje IBICT - em convênio com a Universidade Federal do Rio de Janeiro (UFRJ). A figura demonstra, ainda, que a produção da Universidade Estadual Paulista (UNESP) apresenta um número consideravelmente inferior ao das demais escolas. Isso se deve ao fato de que o programa da referida Universidade é um dos mais recentes do país.

A Figura 3 apresenta a distribuição das teses e dissertações de acordo com as áreas de concentração dos programas no período em questão, demonstrando que há um núcleo em torno da área "Ciência da Informação". 


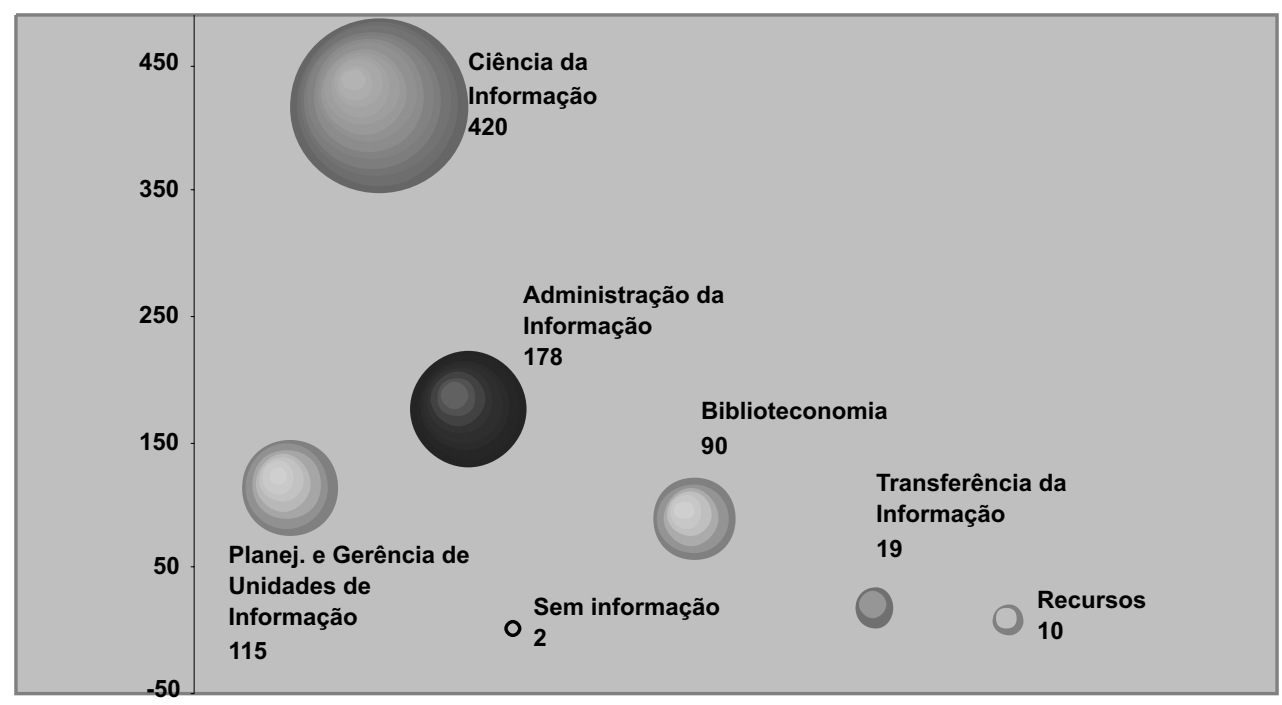

Figura 3. Áreas de concentração.

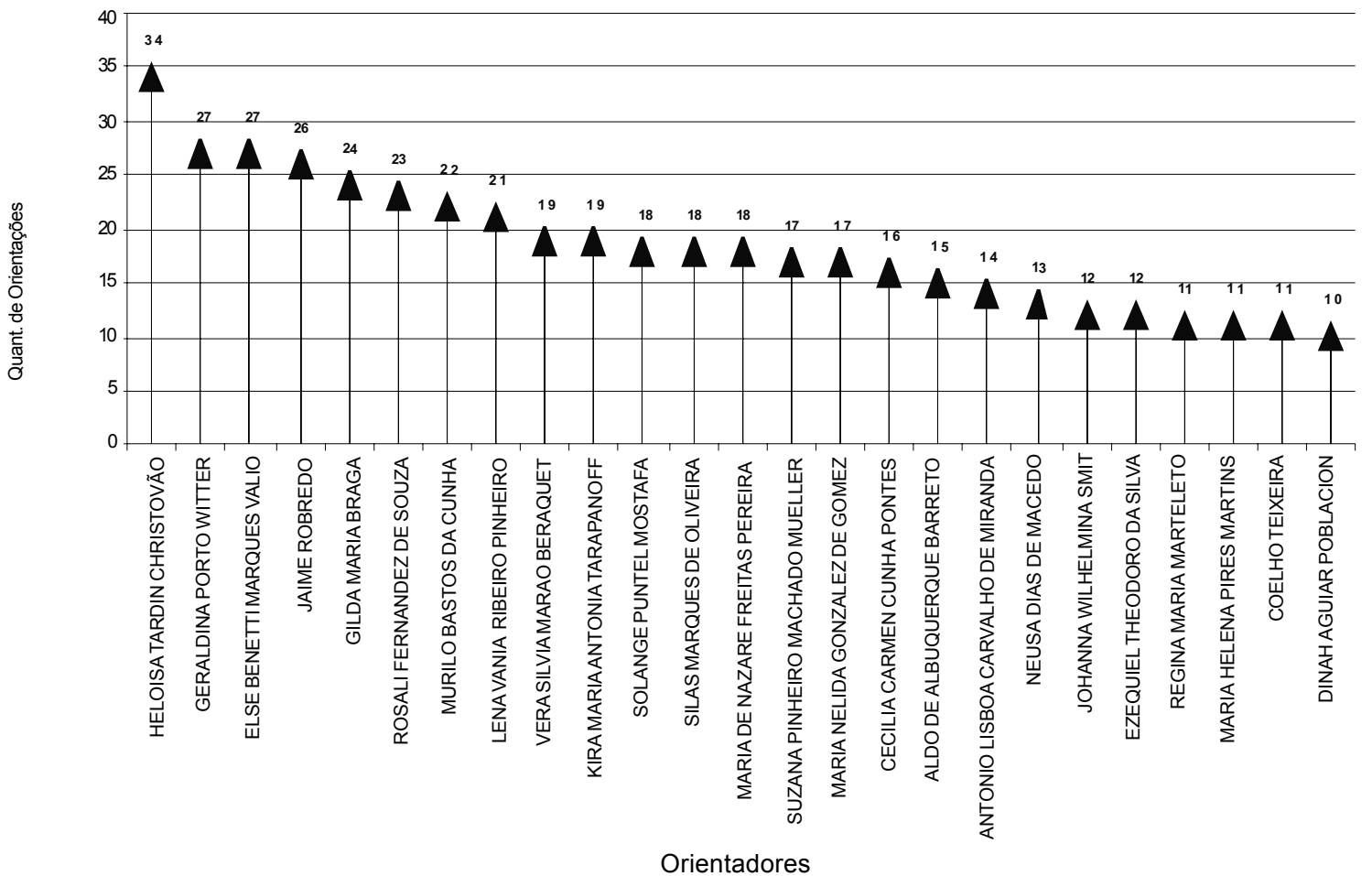

Figura 4. Orientações x orientadores.

A Figura acima apresenta a relação dos docentes que orientaram um número igual ou superior a dez alunos, no período de 1978-2001. A figura permite visualizar que os vinte e cinco docentes indicados acima, orientaram 55\% das teses e dissertações produzidas, constituindo o quadro de professores que ofereceu o maior número de orientações na produção de teses e dissertações no campo da Ciência da Informação, ou seja, os vanguardistas da área. 
Tipologia das Pesquisas

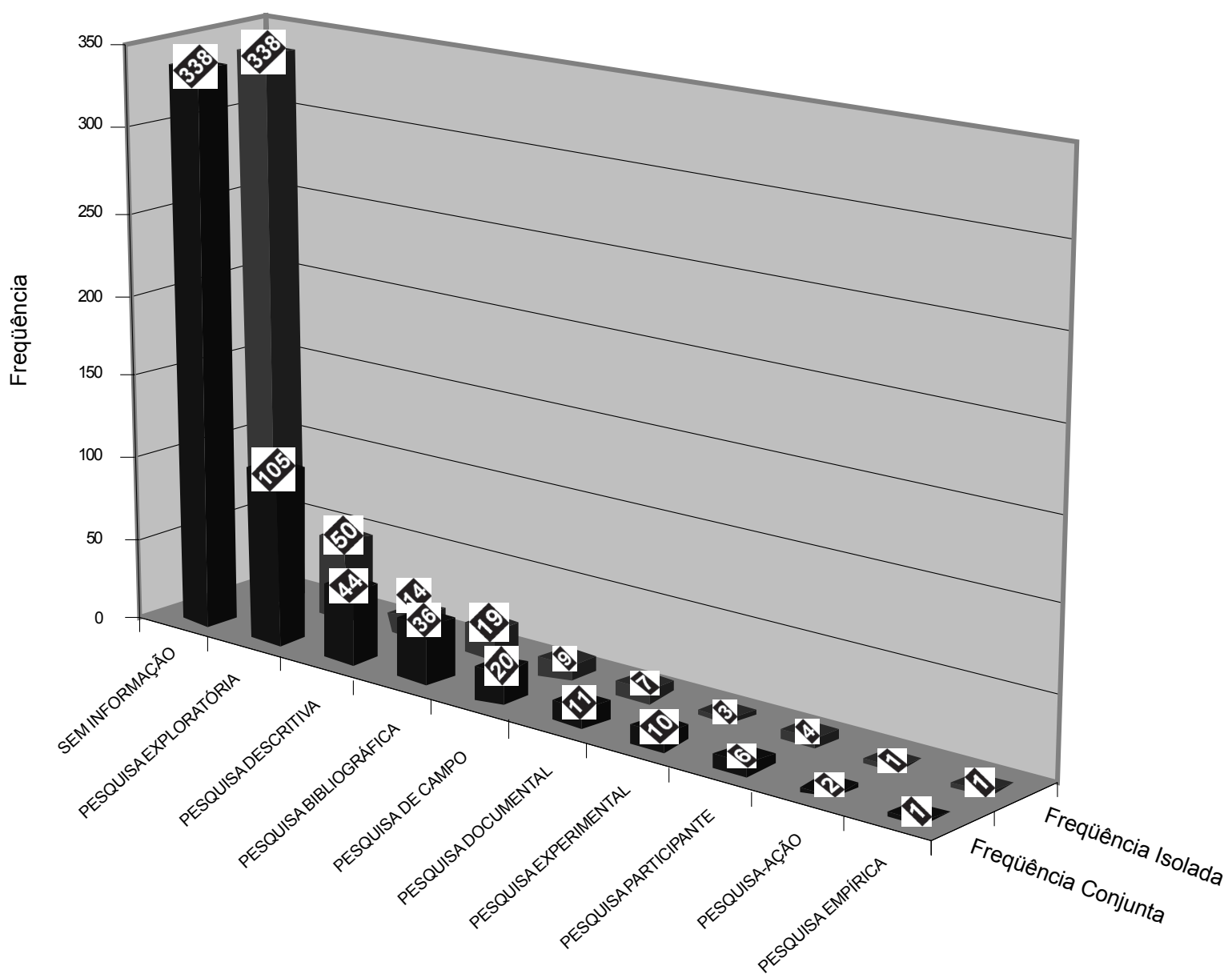

Figura 5. Tipos de pesquisa.

A figura 5 apresenta a tipologia das pesquisas das teses e dissertações analisadas, revelando, em conjunto com o gráfico posterior, que, do corpus pesquisado, apenas 124 trabalhos informaram o tipo de pesquisa e o método utilizados, 263 informaram apenas o método utilizado, 108 informaram apenas o tipo de pesquisa e 338 (40,58\%) não informaram nem o tipo de pesquisa e nem o método utilizado. Em relação aos 338 registros em que o tipo de pesquisa e o método não foram citados, é necessário considerar duas possibilidades: 1) os dados de partida, mais especificamente os resumos, não possibilitaram a identificação dessas informações; 2) as teses e/ ou dissertações foram produzidas sem parâmetros metodológicos.

Em consonância com as indicações da CAPES, revelando que, no campo da Ciência da Informação, a pesquisa está muito voltada para a solução de problemas específicos e locais, não apresentando a generalização tão almejada pela área.

As análises cientométricas relevaram, ainda, considerável pluralidade de métodos e tipos de pesquisas presentes nas teses e dissertações. Percebeuse também que parece haver uma falta de entendimento do que seja pesquisa científica, tipologia de pesquisa, métodos de pesquisa e instrumentos de coleta de dados, ressaltando a necessidade de estudos e de reflexões mais abrangentes, tendo em vista o alcance dos padrões de excelência estabelecidos pela CAPES em relação aos procedimentos de pesquisa, em que teses e dissertações devem mostrar domínio dos procedimentos de pesquisa, utilizando e apresentando-os de maneira adequada. 

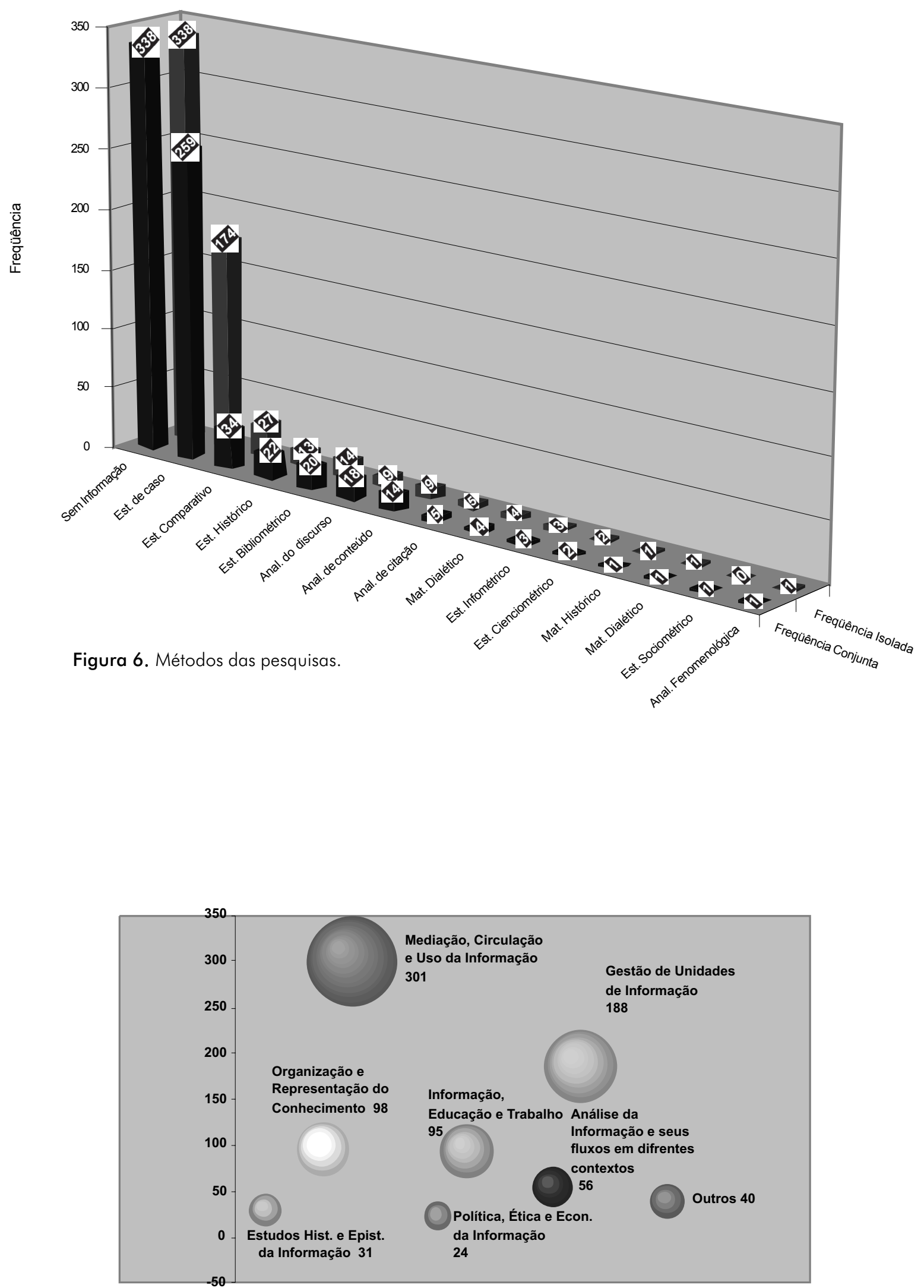

Figura 7. Distribuição das teses e dissertações nos Grupos de Trabalho da ANCIB. 
A Figura 7 apresenta a distribuição das teses e dissertações no âmbito dos grupos temáticos da ANCIB, revelando que o GT 3 "Mediação, Circulação e Uso da Informação" acolheu o maior número de trabalhos até o momento. Tal configuração demonstra que 36,13\% das teses e/ou dissertações analisadas abordaram assuntos relacionados aos processos de fluxos da informação. No entanto percebeu-se que a ementa do referido grupo é demasiadamente abrangente e, por isso, seu destaque configurou-se como uma tendência normal, haja vista que, em função da abrangência do grupo, muitos assuntos foram por ele englobados.

O GT 2 "Organização e representação do conhecimento" agrupou 22,37\% das teses e dissertações, confirmando a permanência da tradição dos estudos da área em relação a esse segmento.

A posição, no gráfico, do GT 1 "Estudos Históricos e Epistemológicos da Informação" confirma as indicações da literatura e da CAPES, revelando um número muito tímido de pesquisas $(3,72 \%)$ que abordam questões de ordem teórica, epistemológica e histórica. Assim, conforme indicações da CAPES, a área deve despender maiores esforços na realização de pesquisas teóricas e conceituais em detrimento das pesquisas empíricas do tipo "estudos de casos".

Por fim, o gráfico indica que 4,80\% das teses e dissertações analisadas não foram passíveis de encaixe nos grupos temáticos da $\mathrm{ANCIB}$. A esse fato atribuemse duas possibilidades: 1 - a tabela da ANCIB não contempla de forma integral os assuntos abordados pelas teses e dissertações; 2 - A área apresenta uma dispersão temática muito grande e alguns temas abordados nas pesquisas estão fora do campo da Ciência da Informação, o que demonstra a necessidade de definição do objeto da área e das temáticas de pesquisa, de acordo com as áreas de concentração e linhas de pesquisa dos programas de pós-graduação para que, assim, os programas possam oferecer efetiva contribuição para a produção do conhecimento no campo da Ciência da Informação. A questão da inserção temática da pesquisa tem sido apontada pela CAPES como elemento balizador no julgamento da formação oferecida e do conhecimento produzido pelos programas.

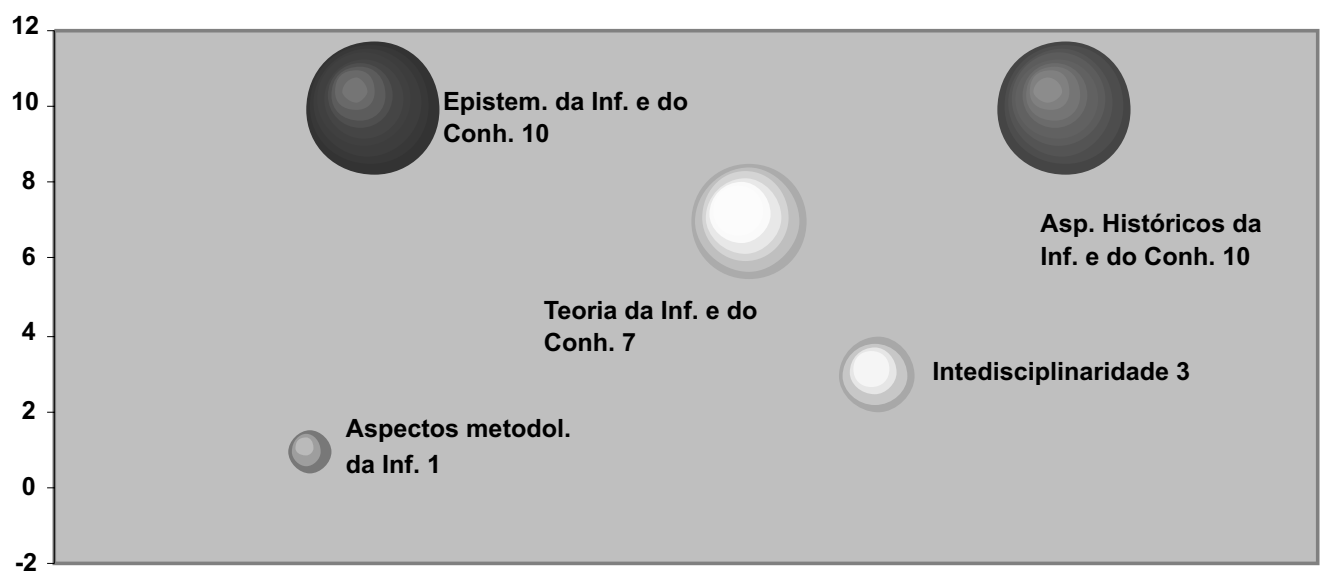

Figura 8. Distribuições das teses e dissertações no G1 "Estudos Históricos e Epistemológicos da Informação".

Percebe-se, pela Figura 8, que no âmbito do GT 1 os aspectos metodológicos da Informação foi o tema com menor ocorrência e em que os aspectos históricos e epistemológicos da informação e do conhecimento apresentaram uma incidência maior, embora os números ainda sejam pouco expressivos. 


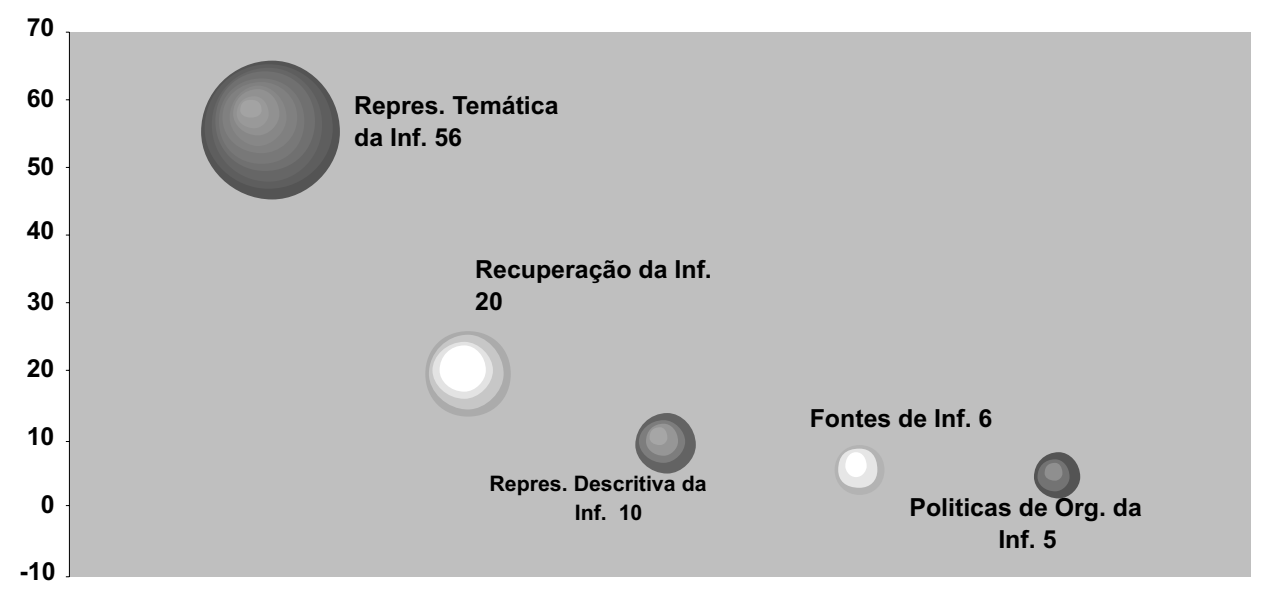

Figura 9. Distribuição das teses e dissertações no G2 "Organização e Representação do Conhecimento".

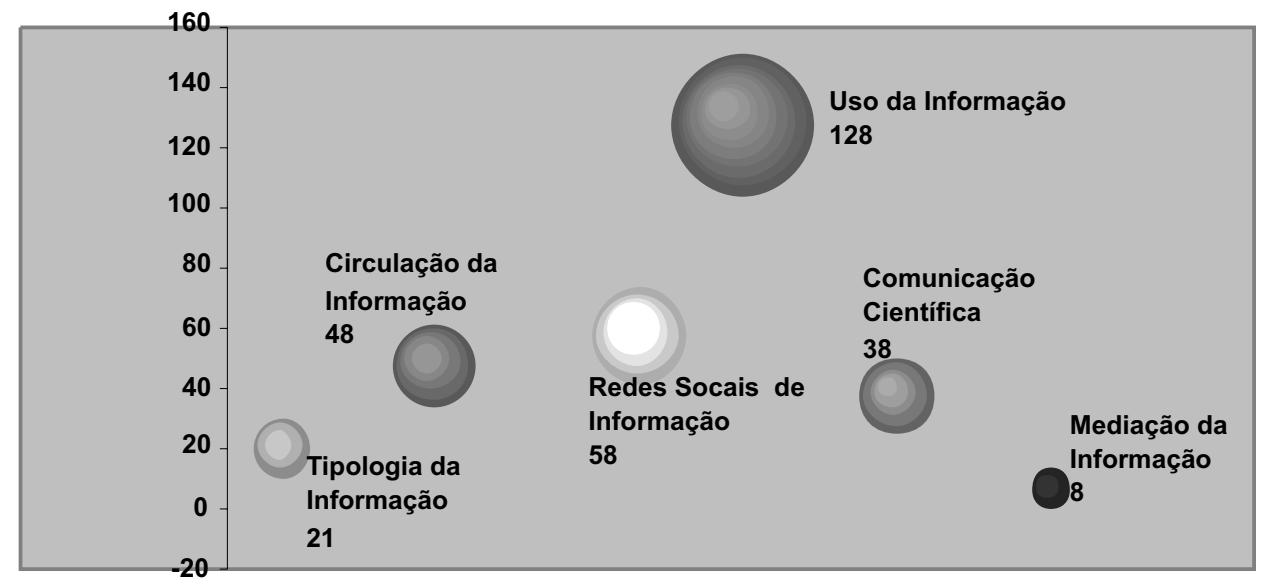

Figura 10. Distribuições das teses e dissertações no G3 "Mediação, Circulação e Uso da Informação".

A Figura 9 apresenta a distribuição das teses e dissertações classificadas no GT 2. Observa-se que as pesquisas que abordam temas relacionados à representação temática e recuperação da informação constituíram o núcleo desse GT, enquanto as teses e dissertações que tratam das políticas de organização do conhecimento representam um universo significativamente menor.

A Figura 10 apresenta a configuração do GT 3 (que abarcou o maior número de teses e dissertações), em que os temas relacionados ao uso da informação foram amplamente abordados. Em seguida, aparecem os temas relacionados às redes sociais de informação, e a ocorrência significativa de trabalhos classificados nesse item pode indicar a ampliação do interesse pelo tema, que aborda questões ligadas à autoria da informação, formas de leitura da informação, estruturas textuais (textos, hipertextos, outras estruturas textuais), informação e novas tecnologias (arquivos abertos, bibliotecas digitais, bases de dados eletrônicas).

As representações da Figura 10 revelam, ainda, que são poucas as pesquisas relacionadas ao tema mediação da informação, a despeito de sua relevância.

No GT 4 o item Gestão de Unidades de Informação contemplou o maior número de trabalhos. Nesse caso, é necessário questionar se as pesquisas têm abordado questões de ordem prática para solução de problemas locais ou se têm tratado de questões acadêmicas e teóricas. 


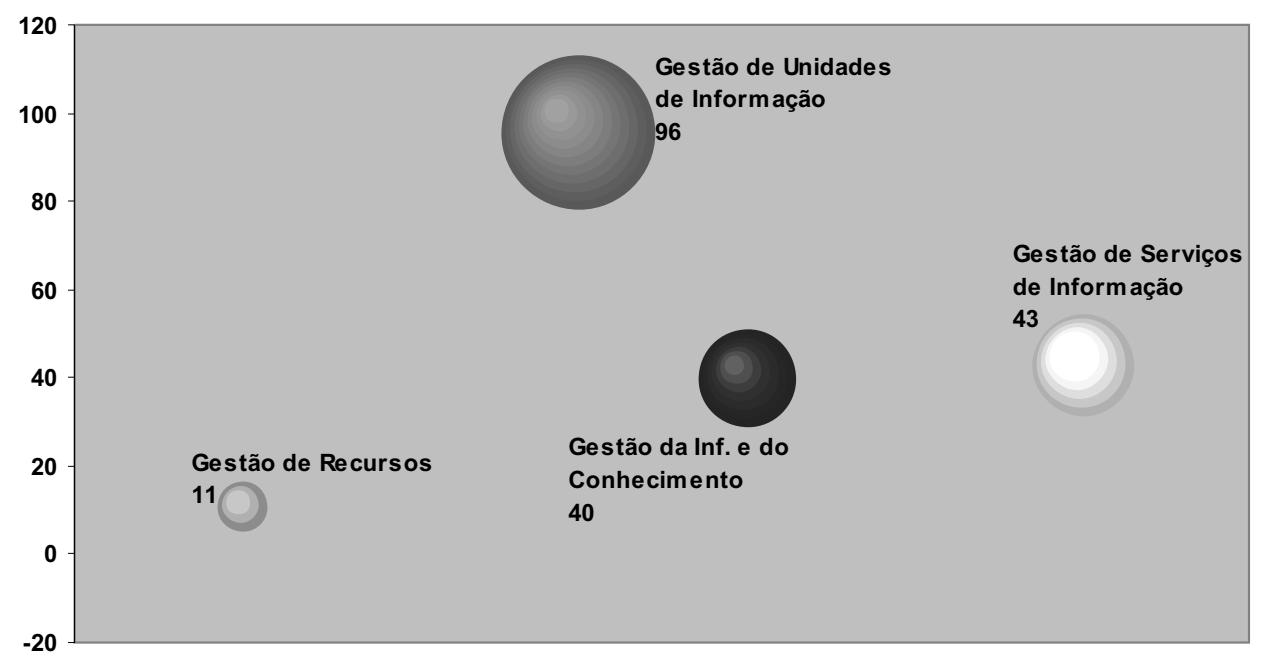

Figura 11. Distribuições das Teses e Dissertações no G4 "Gestão de Unidades de Informação".

Por meio da figura acima, é possível observar ainda que os temas relacionados à gestão da informação e do conhecimento são abordados pelo GT 4 "Gestão de unidades de informação". Julga-se conveniente, no entanto, ressaltar que nas teses e dissertações analisadas as pesquisas que estudaram o tema gestão da informação e do conhecimento não abordavam a gestão das unidades que conduzem tais práticas, mas sim os processos de gestão em si, suas aplicabilidades etc. Dessa forma, para esta pesquisa, a presença dos temas gestão da informação e do conhecimento no âmbito do GT 4 não se mostrou adequada.

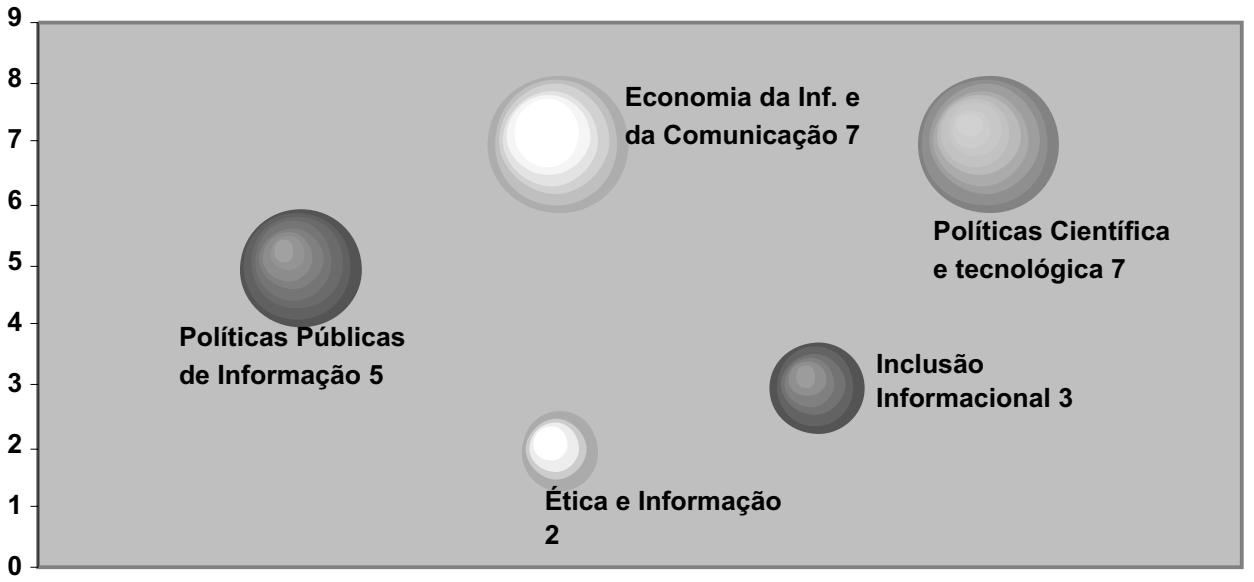

Figura 12. Distribuições das teses e dissertações no G5 "Política, Ética e Economia da Informação".

A análise da figura acima demonstra que no GT 5 (grupo que abarcou o menor número de teses e dissertações, apenas 2, $88 \%$ do universo pesquisado), os temas ética e informação e inclusão informacional apresentam a menor freqüência: apenas 2 e 3 casos, respectivamente. Já os temas relacionados às políticas cientificas e tecnológicas e à economia da informação e do conhecimento apresentam um número um pouco maior, mais ainda assim bastante inexpressivo. 
O GT 5, assim como o GT 1, receptou um número baixo de teses e dissertações, temas cruciais para o desenvolvimento e crescimento da Ciência da Informação no Brasil. Assim, os temas desses grupos devem ser alvo de maior atenção da Ciência da Informação.

Observa-se, por meio da Figura 13, que as pesquisas relacionadas à formação do profissional da informação constituem um universo bastante expressivo no âmbito do GT 6. Frente a essa constatação, é importante considerar que o item formação do profissional da informação configura-se como um item consideravelmente abrangente, abordando questões como sistema educacional em Ciência da Informação (graduação e pós-graduação), formação e desenvolvimento profissional (estatuto do profissional da informação), profissional da informação (atividade e atuação profissional, campo de trabalho e imagem do profissional da informação, competências e perfil profissional), associações e entidades de classes. Dessa forma, no âmbito da presente pesquisa, o item em questão se mostrou muito plural e extensivo.

Por fim, a Figura 14 indica que a Ciência da Informação tem deixado de explorar um importante ramo do campo, que são os indicadores de autoria, de produção científica e de produção tecnológica, tratados no âmbito dos métodos quantitativos de análise da informação e de seu comportamento. O núcleo do GT 7 direciona-se para os estudos que abordaram temas relacionados à avaliação da informação.

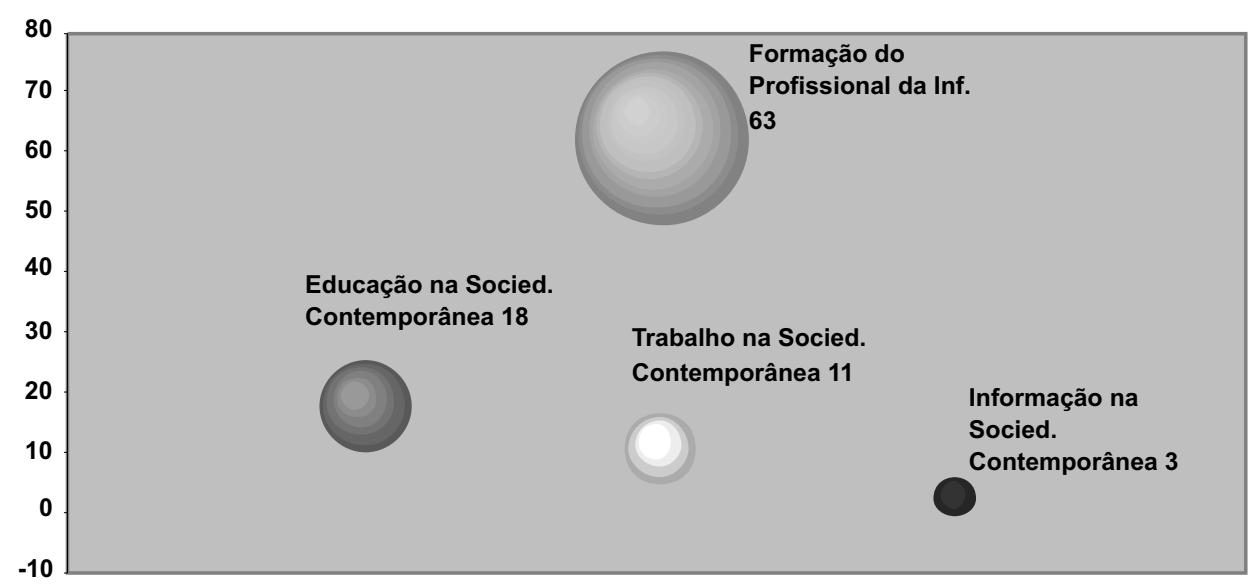

Figura 13. Distribuições das teses e dissertações no G6 "Informação, Educação e Trabalho".

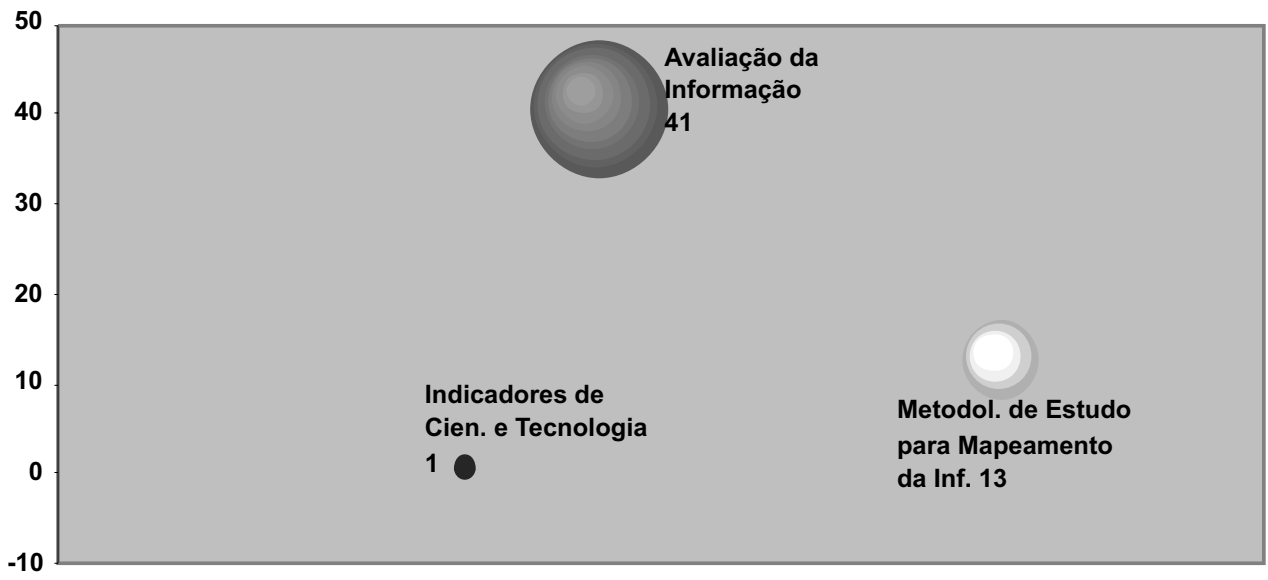

Figura 14. Distribuições das teses e dissertações no G7 "Análise da Informação e seus Fluxos em Diferentes Contextos". 


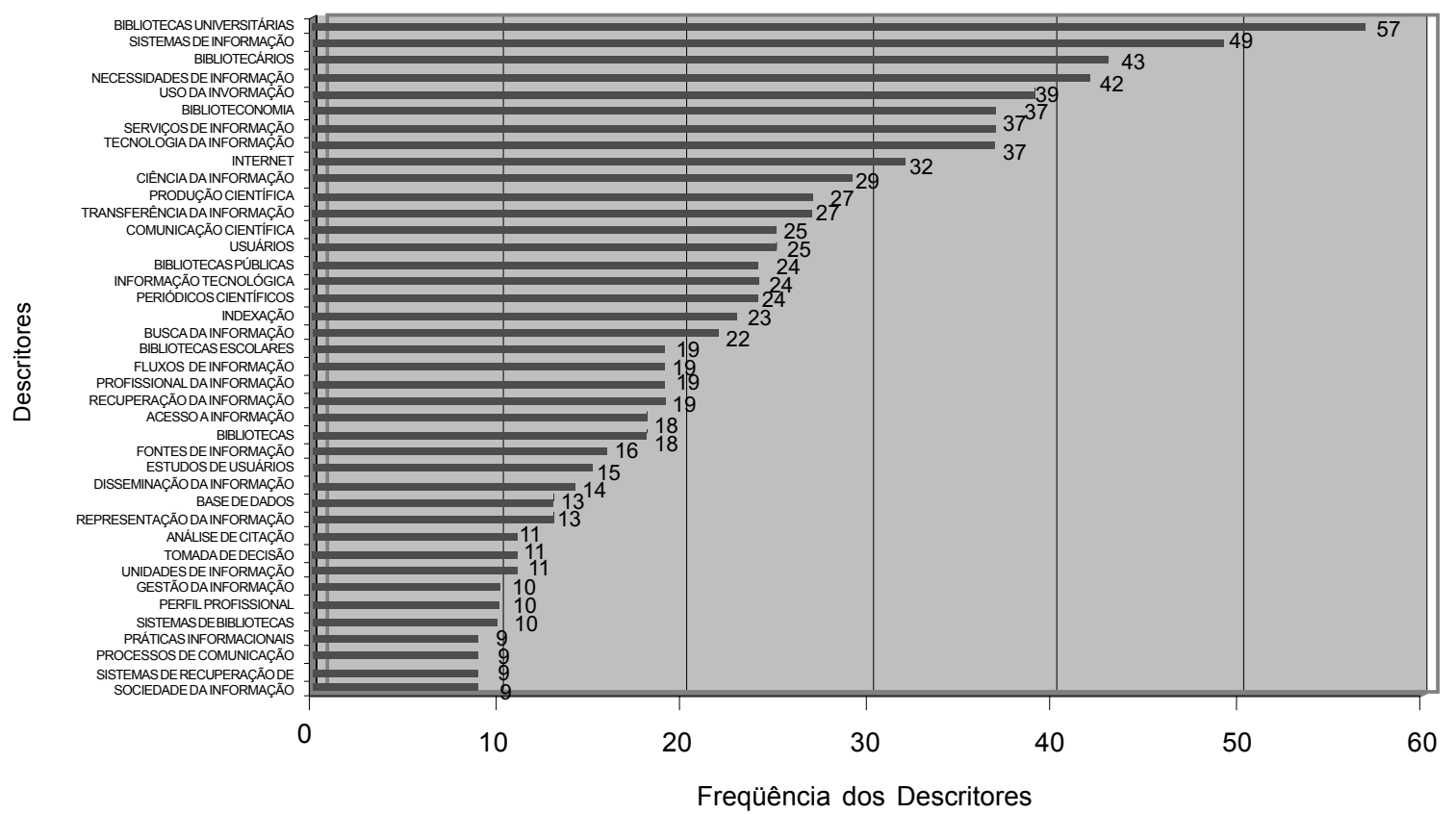

Figura 15. Temas dsa Teses e Dissertações.

A Figura 15 expõe os termos que apresentaram freqüência igual ou superior a nove nos temas de pesquisas das teses e dissertações analisadas. Percebese que o tema bibliotecas universitárias encabeça o "ranking", tendo sido identificado em 57 teses e/ ou dissertações. Mais uma vez parece ficar evidente que as pesquisas da área ainda apresentam uma perspectiva prática direcionada para solução de problemas específicos e localizados. A figura também demonstra que grande foi o número de pesquisas que abordaram os processos de fluxos informacionais, como necessidades e uso da informação. O termo "sociedade da informação" também aparece na figura e, embora esteja ocupando o último lugar no ranking, a aparição desse termo demonstra que, apesar da sua relativa pouca idade, este tema já foi alvo de um número razoável de pesquisas.

A análise mais genérica da figura revela que as pesquisas se orientam para a gestão de produtos e serviços de informação, para a organização da informação, para os usuários e para a formação do profissional bibliotecário. Nota-se a ausência de termos relacionados aos aspectos históricos da Biblioteconomia e da Ciência da Informação, bem como de termos que apresentem ligações com os fundamentos, as metodologias e os aspectos epistemológicos da área. Diante disso, é necessário destacar que a CAPES considera a inserção das pesquisas no campo teórico como crucial para o desenvolvimento da Ciência da Informação no Brasil, ou seja, é necessário que a área se dedique intensamente ao desenvolvimento de pesquisas que abordem questões teóricas e conceituais para que, assim, alcance maior maturidade científica e garanta sua efetiva institucionalização.

\section{CONSIDERAÇÕES FINAIS}

A pesquisa foi desenvolvida com o objetivo de estudar a institucionalização da Ciência da Informação no Brasil, por meio da verificação do grau de convergência entre a produção científica - materializada em teses e dissertações - e os marcos regulatórios da área (Documento de Área da CAPES e Grupos Temáticos da ANCIB).

As representações gráficas geraram resultados importantes para a política de pesquisa da área, dentre os quais se destacam: o número de doutores na área é ainda bastante incipiente, insuficiente para consolidar o ensino e a pesquisa da área; o estudo de casos ainda é um método amplamente utilizado na área e constitui a tônica das teses e dissertações; os assuntos relacionados aos processos de mediação, circulação e uso da informação têm presença significativa, revelando-se como tendência nuclear da área; observase, pelos resumos de teses e dissertações, que persiste 
na área, ainda, a perspectiva prática, direcionada para a solução de problemas específicos e localizados.

Vale ressaltar que várias outras questões ficaram evidentes, sendo a primeira delas a que diz respeito à qualidade das bases referenciais de teses e dissertações do país que, via de regra, apresentam inconsistências por falta de padronização dos dados bibliográficos e de representação temática. Dessa forma, faz-se necessário dispensar maior atenção à qualidade dessas bases para que elas possam ser utilizadas não apenas como instrumentos de recuperação da informação, mas também como instrumentos que viabilizem a construção de indicadores capazes de respaldar o desenvolvimento de políticas científicas e possibilitar a avaliação da produção científica brasileira.

A pesquisa evidenciou que, atualmente, a construção desses indicadores só se torna possível com a construção de bases de dados ad hoc. Sua construção, no entanto, é um trabalho árduo e, por vezes, até inviável, pois, em muitos casos, os dados de partida são incompletos, portanto problemáticos quanto à representatividade do universo da produção nacional de dissertações e teses. A falta de padronização dos dados - tanto bibliográficos quanto temáticos, aqui incluídos os descritores e os resumos - são fatores que podem comprometer os resultados de pesquisas que não levem em conta esses aspectos; com efeito, os resumos que poderiam concorrer para uma caracterização mais adequada das dissertações e teses são, muitas vezes, vagos e pouco informativos. Nesse sentido, recomenda-se que os programas de Pósgraduação em Ciência da Informação passem a exigir maior rigor na padronização dos dados bibliográficos e na formatação das teses e dissertações, tendo como parâmetro as normas da Associação Brasileira de Normas Técnicas (ABNT).

Uma segunda questão a ser considerada diz respeito à metodologia empregada nesta pesquisa, que apresenta caminhos alternativos para o estudo da institucionalização da pesquisa científica, do seu mapeamento e avaliação por meio das bases de teses e dissertações. Kobashi e Santos (2006), como já foi dito anteriormente, consideram que as teses e dissertações são fontes imprescindíveis para mapear a ciência produzida no país. A importância das teses e dissertações para o mapeamento da pesquisa justificase em função de seu significado na cadeia da pesquisa em uma área. $\bigcirc$ crescente interesse em registrar e disponibilizar esses tipos de documentos em bases de dados institucionais deverá, no entanto, ser acompanhado de maior rigor na elaboração das bases de dados de dissertações e teses de âmbito nacional.

E ainda, uma terceira questão a ser ressaltada refere-se à configuração do Grupo de Trabalho 3 da ANCIB "Mediação, Circulação e Uso da Informação". Observou-se, no contexto da presente pesquisa, que sua descrição é demasiadamente abrangente e, assim, sugere-se um estudo da conformação desse grupo e sua reformulação, de modo a evidenciar-lhe uma identidade mais específica. Ainda em relação aos grupos temáticos, percebeu-se, na prática, que o encaixe de temas relacionados à gestão da informação e do conhecimento, no âmbito do Grupo de Trabalho 4 "Gestão de Unidades de informação", não é adequado visto que as teses e dissertações que pesquisaram tais temas não abordavam a gestão das unidades que conduzem tais práticas, mas sim processos de gestão em si, suas aplicabilidades etc. Nesse caso, também se considera de suma importância a análise e reorganização.

Por fim, verifica-se que as teses e dissertações apresentam convergência parcial com os marcos regulatórios da área. Tal afirmação respalda-se na constatação de que as teses e dissertações produzidas pelos programas de Pós-graduação em Ciência da Informação atendem parcialmente ao disposto no Documento de Área da CAPES. É, portanto, necessário superar alguns desafios para, então, garantir a institucionalização social e cognitiva efetiva da Ciência da Informação como campo de pesquisa. Nesse sentido, as representações gráficas, em consonância com os parâmetros da CAPES, indicam a necessidade de diminuição do elevado número de estudos direcionados para a prática e reforça a necessidade de garantir a produção de pesquisas teóricas e conceituais, em detrimento das pesquisas que visem à resolução de problemas concretos, como muitos tipos de estudos de casos - fato que vem sendo apontado pela CAPES como um fator crítico para o sucesso e crescimento da área; a necessidade de definição do objeto de estudo da Ciência da informação, evitando-se a dispersão temática existente na área; necessidade de definição metodológica (tipologia de pesquisa, métodos e técnicas de pesquisa e instrumentos de coleta de dados) das pesquisas desenvolvidas; necessidade de crescimento dos programas de Pós-graduação, principalmente em relação aos cursos de doutorado. 
Em relação aos grupos temáticos da ANCIB, percebeu-se, por meio das análises dos gráficos, que, apesar de os grupos terem abarcado $95,20 \%$ do corpus analisado, há itens que, ou por lacunas da tabela da ANClB ou pela dispersão temática da área, não foram passíveis de classificação nos grupos.

Acredita-se que a pesquisa desenvolvida levantou dados que poderão dar suporte à elaboração de novas hipóteses e que os resultados apresentados devem ser verticalizados e validados, de modo a se obter conhecimento crescente sobre o campo da Ciência da informação. Vale ressaltar que este não é um trabalho conclusivo, mas traz hipóteses e subsídios para o aprofundamento de tão relevante discussão.

\section{REFERÊNCIAS}

BUFREM, L.; PRATES, Y. O saber científico registrado e as práticas de mensuração da informação. Ciência da Informação, v.34, n.2, p.9-25, 2005. Disponível em: <http://www.scielo.br>. Acesso em: 10 mar. 2006.

COORDENAÇÃO DE APERFEIÇOAMENTO DE PESSOAL DE NIIVEL SUPERIOR - CAPES. 2004. Documento de área: Comunicação e Ciência da Informação. Disponível em: <http:// www.capes.gov.br/capes/portal/conteudo/ 2003_031_Doc_Area.pdf>. Acesso em: 05 nov. 2005.

GOMES, M.Y.F.S.F. Análise das dissertações defendidas no programa de pós-graduação em Ciência da Informação da UFMG, na década de 1990. In: ENCONTRO NACIONAL DE PESQUISA EM CIÊNCIA DA INFORMAÇÃO, 6., 2005, Florianópolis. Anais... Florianópolis, UFSC, 2005. p.1-12.

GOMES, M.Y.F.S.F. Tendências atuais da produção científica em Biblioteconomia e Ciência da Informação no Brasil. DataGramaZero - Revista de Ciência da Informação, v.7, n.3, 2006. Disponível em: <http://www.dgzero.org > Acesso em: 20 jul. 2006.

KOBASHI, N.Y.; SANTOS, R.N.M.; CARVALHO, J.O.F. Cartografia de dissertações e teses: uma aplicação à área de ciência da informação. In: SEMINÁRIO NACIONAL DE BIBLIOTECAS UNIVERSITÁRIAS, 14., 2006, Salvador. [Anais eletrônicos...] Salvador: UFBA, 2006. 1 CD-ROM.

KOBASHI, N.Y.; SANTOS, R.N.M. Institucionalização da pesquisa científica no Brasil: cartografia temática e de redes por meio de técnicas bibliométricas. Transinformação, v. 18, n. 1, p.27-36, 2006.

MACIAS-CHAPULA, C.A. O papel da informetria e da cienciometria e sua perspectiva nacional e internacional. Ciência da Informação, v.27, n.2, p.134-140, 1998. Disponível em: $<$ http://www.scielo.br>. Acesso em: 15 nov. 2005.
MIRANDA, A.; BARRETO, A.A. Pesquisa em Ciência da Informação no Brasil: síntese e perspectiva. DataGramaZero - Revista de Ciência da Informação, v. 1, n.6, 2000. Disponível em: <http:// www. datagramazero.org.br>. Acesso em: 3 mar. 2005.

OLIVEIRA, M.; SANTANA, M.A.L. V ENANCIB: análise dos caminhos de pesquisa. . In: ENCONTRO NACIONAL DE PESQUISA EM CIÊNCIA DA INFORMAÇÃO, 6., 2005, Florianópolis. Anais... Florianópolis, UFSC, 2005. p.1-12

PINHEIRO, L.V.R.; LOUREIRO, J.M.M. Traçados e limites da Ciência da Informação. Ciência da Informação, v.24, n. 1, 1995. Disponível em: <http://www.ibict.br>. Acesso em: 20 maio 2005.

PARLEMITI, R; POLITY, Y. Dynamiques de I'institucionalisation sociale et cognitive dês sciences de l'information. In: BOURE, R. (ed). Les origines dês Sciences de l'information et de la communication: regards croisés. Paris: PUS, 2002. p. 95-123.

ROBREDO, J. Informação, conhecimento e Ciência da Informação. In: ROBREDO, J. Da Ciência da Informação revisitada aos sistemas humanos de informação. Brasília: SSRR Informações; Thesaurus, 2003. p.1-103.

SPINAK, E. Indicadores cienciométricos. Ciência da Informação, Brasília, v.27, n.2, p.141-148, 1998. Disponível em: <http:// www.scielo.br>. Acesso em: 15 nov. 2005.

VAN RAAN, A. F. J. The use of bibliometric analysis in research performance assessment and monitoring of interdisciplinary scientific developments. Technikfolgenabschätzung-Theorie und Praxis/Technology Assessment-Theory and Practice, v. 1, n. 12, p. 20-29, mar. 2003

WERSIG, G. Information science: the study of postmodern knowledge usage. Information Processing \& Management, v. 29, n. 2, p. 229-239, 1993. 